\title{
Characterization of the chromosomal inversion associated with the Koa mutation in the mouse revealed the cause of skeletal abnormalities
}

\author{
Kentaro Katayama ${ }^{\dagger 1,3}$, Sayaka Miyamoto ${ }^{\dagger 1}$, Aki Furuno ${ }^{1}$, Kouyou Akiyama ${ }^{1}$, \\ Sakino Takahashi ${ }^{2}$, Hiroetsu Suzuki ${ }^{3}$, Takehito Tsuji ${ }^{1}$ and Tetsuo Kunieda*1
}

\author{
Address: ${ }^{1}$ Graduate School of Natural Science and Technology, Okayama University, Okayama 700-8530, Japan, ${ }^{2}$ Tokyo University of Agriculture \\ and Technology, Tokyo 184-8588, Japan and ${ }^{3}$ Laboratory of Veterinary Physiology, Nippon Veterinary and Life Science University, Tokyo 170- \\ 0071, Japan \\ Email: Kentaro Katayama - katayama@nvlu.ac.jp; Sayaka Miyamoto - say-miyamoto@iskweb.co.jp; Aki Furuno - aki.furuno@jfcr.or.jp; \\ Kouyou Akiyama - kakiyama@isc.meiji.ac.jp; Sakino Takahashi - sakinotk@nifty.com; Hiroetsu Suzuki - hiroetsu@nvlu.ac.jp; \\ Takehito Tsuji - takehito@cc.okayama-u.ac.jp; Tetsuo Kunieda* - tkunieda@cc.okayama-u.ac.jp \\ * Corresponding author †Equal contributors
}

Published: 22 September 2009

BMC Genetics 2009, 10:60 doi:10.1 |86/147|-2156-10-60

This article is available from: http://www.biomedcentral.com//47/-2/56/10/60

(C) 2009 Katayama et al; licensee BioMed Central Ltd.

This is an Open Access article distributed under the terms of the Creative Commons Attribution License (http://creativecommons.org/licenses/by/2.0), which permits unrestricted use, distribution, and reproduction in any medium, provided the original work is properly cited.

\begin{abstract}
Background: Koala (Koa) is a dominant mutation in mice causing bushy muzzle and pinna, and is associated with a chromosomal inversion on the distal half of chromosome 15. To identify the gene responsible for the Koa phenotypes, we investigated phenotypes of Koa homozygous mice and determined the breakpoints of the inversion with a genetic method using recombination between two different chromosomal inversions.
\end{abstract}

Results: Skeletal preparation of Koa homozygotes showed marked deformity of the ribs and a wider skull with extended zygomatic arches, in addition to a general reduction in the lengths of long bones. They also had open eyelids at birth caused by a defect in the extension of eyelid anlagen during the embryonic stages. The proximal and distal breakpoints of the Koa inversion were determined to be $0.8-\mathrm{Mb}$ distal to the Trsps I gene and to 0.I-Mb distal to the Hoxc4 gene, respectively, as previously reported. The phenotypes of mice with the recombinant inverted chromosomes revealed the localization of the gene responsible the Koa phenotype in the vicinity of the proximal recombinant breakpoint. Expression of the TrspsI gene in this region was significantly reduced in the Koa homozygous and heterozygous embryos.

Conclusion: While no gene was disrupted by the chromosomal inversion, an association between the Koa phenotype and the proximal recombinant breakpoint, phenotypic similarities with Trps /deficient mice or human patients with TRSPI mutations, and the reduced expression of the Trsps I gene in Koa mice, indicated that the phenotypes of the Koa mice are caused by the altered expression of the Trps / gene. 


\section{Background}

Many chromosomal rearrangements including translocation, insertion, deletion and inversion have been reported in mice, and they are often associated with developmental disorders [1]. In general, the developmental defects associated with chromosomal inversions are caused by disruption and/or alternation of expression of gene(s) located on or in the vicinity of breakpoints of the inversion [2,3]. Koala (Koa) is a dominant mutation of the mouse originating from X-ray irradiation to a $\mathrm{C} 3 \mathrm{H} / \mathrm{HeH}$ male mouse in the MRC Radiology Unit and it is associated with chromosomal inversion on the distal half of chromosome 15 $[4,5]$. Koa heterozygotes $(\mathrm{Koa} /+)$ have bushy muzzle and pinna, whereas Koa homozygotes (Koa/Koa) exhibit open eyelids at birth (EOB), dwarfism, and a flatter and broader head in addition to the phenotypic features of $\mathrm{Koa} /+$ mice $[4,5]$, but the exact phenotypes of Koa/Koa have not been described. Recently, Fantauzo et al [6] reported the localization of the breakpoints of the Koa inversion and reduced expression of Trps 1 gene in a region close to the breakpoint, but exact assosiation between the Koa phenotype and the reduced expression of the Trps1 gene has not been confirmed.

Eh is another mutation of the mouse associated with a chromosomal inversion on the distal half of chromosome 15 overlapping with the inverted region of the Koa mutation $[7,8]$. We previously identified both proximal and distal breakpoints of the Eh inversion by a new genetic method that uses recombinant chromosomes generated by crossing-over between the inverted regions of the Eh and Koa mutations [9]. In the present study, we characterized the breakpoints of the chromosomal inversion of the Koa mutation and assigned the candidate region for the Koa phenotype by using the recombinant chromosomes to determine the gene responsible for the Koa phenotypes. We also investigated phenotypes of Koa/Koa mice including skeletal abnormalities, to further characterize the phenotypic features of the Koa mutation, which indicated phenotypic similarity between the Koa mouse and Trps1/ TRPS1 deficient mice or humans. Our findings provide further evidence demonstrating that reduced expression of the Trps1 gene is responsible for the Koa phenotype.

\section{Results}

\section{Phenotypes of the Koa/Koa mice}

Comparison of the body length and weight among different genotypes confirmed dwarfism in Koa/Koa mice. As shown in Figure 1, Koa/Koa mice were slightly smaller than $+/+$ and Koa/+ mice at post natal day 2 (P2) and the differences became more obvious in later stages. The average length and weight of the Koa/Koa mice at P20 were approximately $75 \%$ and $45 \%$ of those of $+/+$ mice, respectively. The Koa/+ mice were also slightly smaller than the $+/+$ mice.

The skeletal preparation of Koa/Koa mice showed that the shapes of the long bones of the limbs, digits, and vertebrae of Koa/Koa appeared to be normal, but the lengths of the long bones were significantly shorter than those of the $+/+$ mice (Table 1). Therefore, the dwarf phenotype observed in Koa/Koa mice may be due to a general reduc-
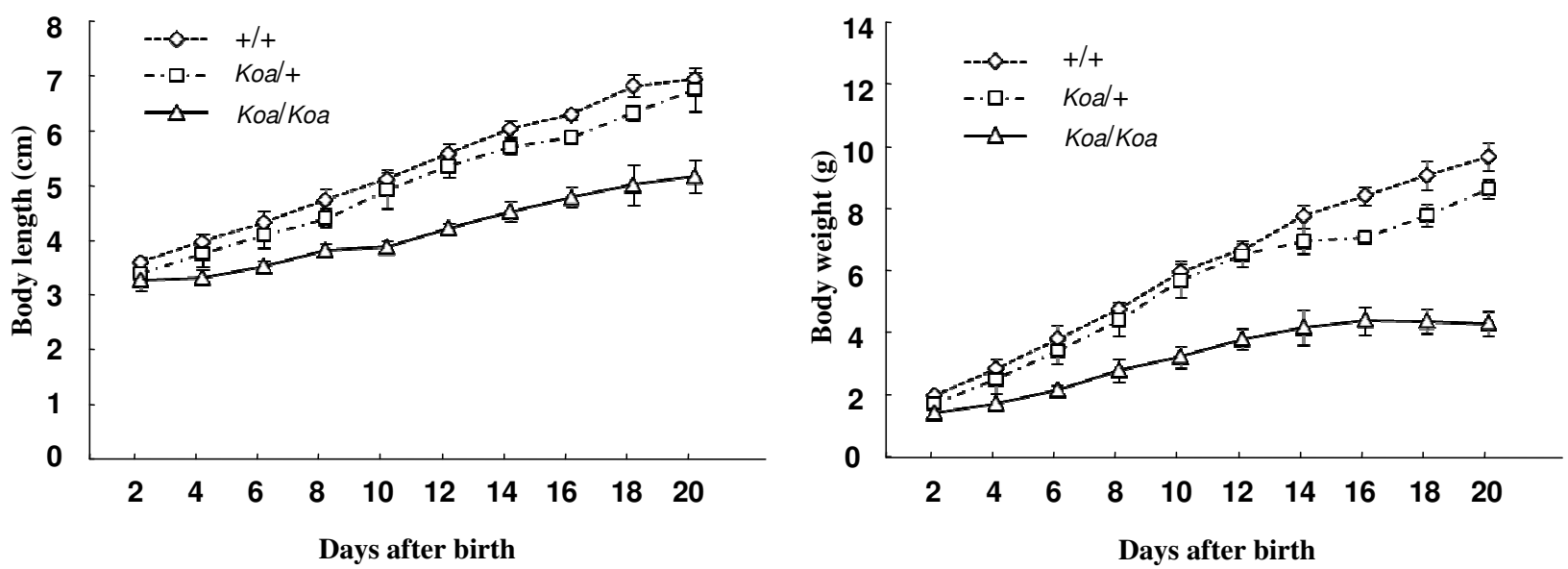

\section{Figure I}

Body length and weight of Koa mice. Body length (left) and weight (right) of Koa/Koa, Koa/+, and +/+ mice were measured until 20 days after birth. Data are shown as the means \pm SDs. The differences in body length were significant at postnatal days 4 to 20 between Koa/Koa and +/+ and days 14 to 18 between Koa/+ and +/+. The differences in body weight were significant at postnatal days 2 to 20 between Koa/Koa and $+/+$ and days 14 to 20 between Koal+ and $+/+$. $(P<0.05)$. 
Table I: Comparison of bone lengths between Koa/Koa and +/+ mice

\begin{tabular}{|c|c|c|c|c|c|}
\hline \multirow[b]{2}{*}{ Genotype } & \multirow[b]{2}{*}{ tibia } & \multirow[b]{2}{*}{ femur } & \multicolumn{3}{|c|}{ Skull } \\
\hline & & & Length & Width & W/L \\
\hline Koa/Koa $(n=3)$ & $15.9 \pm 1.0 *$ & $12.7 \pm 0.8^{* *}$ & $20.9 \pm 1.6^{*}$ & $13.6 \pm 1.0$ & $0.65 \pm 0.02^{* *}$ \\
\hline$+/+(n=3)$ & $18.3 \pm 0.6$ & $15.5 \pm 0.4$ & $24.4 \pm 0.2$ & $14.1 \pm 0.05$ & $0.58 \pm 0.01$ \\
\hline
\end{tabular}

Values represent means \pm SEM. *Statistically significant $(P<0.05)$. **Statistically significant $(P<0.005)$. W/L represents ratios of skull width and length.

tion in the length of the long bones. However, the ribs and skull of Koa/Koa mice showed morphological abnormalities. As shown in Figure 2, marked deformities of costicartilage were observed in the ribs of Koa/Koa mice. The skulls of Koa/Koa mice were reduced in size along the anterior- posterior axis, but the left-right axes were almost the same as $+/+$ mice (Table 1 ). In particular, zygomatic arches were expanded and zygomatic processes were deformed in Koa/Koa mice (Figure 2). The expanded zygomatic arches are likely to be the cause of the flatter and broader shape of the head in Koa/Koa mice. Skeletal preparations of $\mathrm{Koa} /+$ mice showed no apparent bone abnormalities including the ribs and skull (data not shown).

Next, we examined the eyelids of newborn mice to confirm EOB of Koa/Koa. As shown in Table 2, 19 of $21 \mathrm{Koa} /$ Koa mice showed EOB, while 2 of them were normal. In addition, 2 of $30+/$ Ko a mice showed EOB. Next, we examined the development of the eyelids in Koa/Koa embryos by histological examination. Anlagen of both the upper and lower eyelids of $+/+$ embryos formed at embryonic day (E) 13.5, grew at E14.5, and extended and fused with each other at E16.5. In Koa/Koa embryos, both eyelids' anlagen formed and grew at E 14.5, but did not extend and fuse with each other at E16.5 (Figure 3). Therefore, the EOB observed in Koa/Koa mice was caused by defects in the extension of the eyelid anlagen. In the present study, we also found a reduced number of vibrissae in the Koa/Koa mice (data not shown).

\section{Localization of the break points of the Koa inversion}

We previously localized the proximal and distal breakpoints of the Koa inversion to regions between microsatellite markers D15Mit151 and D15Mit143 and between D15Mit15 and D15Mit78 on mouse chromosome 15, respectively [8]. In the present study, we employed a genetic method using a recombinant chromosome generated by crossing-over between the inverted regions of the Eh and Koa mutations, which has been described previously [9], to identify the exact breakpoints of the Koa inversion and the association between genes in the vicinities of the breakpoints and the Koa phenotype. We obtained 60 offspring from mating between $\mathrm{Eh}+/+\mathrm{Koa}$, which possess both Koa and Eh chromosomes (Figure 4), and JF1/Ms. Due to the recombination between the Koa and Eh inverted regions, 15 of them had a deletion of the region flanked by the proximal breakpoints of the Koa and Eh inversions (B in Figure 4) and duplication of the region flanked by the distal breakpoints (D) (DelB-DupD in Figure 4), whereas 13 of them had a duplication of $B$ and deletion of D (DupB-DelD) [8](Katayama et al., 2007, our unpublished data). It is notable that the DelB-DupD mice showed the Koa phenotype while the DupB-DelD mice showed the Eh phenotype. We genotyped 6 microsatellite markers (D15Mok10-15) located on a region close to the expected proximal breakpoint in these mice (Figure 5). The results indicated that D15Mok13-15 showed only the JF1 allele in the 15 DelB-DupD mice, while D15Mok10-12 showed heterozygosity of JF1/Koa or Eh alleles in all 60 mice. These findings indicate that D15Mok13-15 are localized in the deleted region (B), while D15Mok10-12 are localized on the outside of the Koa inversion. Therefore, the proximal breakpoint of the Koa inversion was localized within a 11-kb region between D15Mok12 and D15Mok13 (Figure 5). Next, we genotyped another 5 microsatellite markers (D15Mok16-20) located on a region close to the expected distal breakpoint. D15Mok16-18 showed only the JF1 allele in the 13 DupB-DelD mice, while D15Mok19 and 20 showed heterozygosity of JF1/ Koa or Eh alleles in all 60 mice. These findings indicated the localization of the distal breakpoint of the Koa inversion within a 5.2-kb region between D15Mok18 and D15Mok19 (Figure 5).

We then attempted a series of PCR amplifications in the $11-\mathrm{kb}$ and 5.2-kb regions from $+/+$ and Koa/Koa genomic DNA. In the proximal region, 7 pairs of primers covering the entire 11 -kb region were used for PCR amplification. Six of them amplified fragments with the expected size from both +/+ and Koa/Koa DNA. However, the one remaining fragment flanked by primers Prox-f and Prox-r (Figure 5 and Additional File 1) were not amplified from Koa/Koa DNA, while the fragment was amplified from +/ + DNA. Therefore, the proximal breakpoint was suggested to be localized in this fragment. Similarly, one of the 5 fragments in the distal region flanked by primers Dist- $f$ and Dist-r (Figure 5 and Additional file 1) was not amplified from Koa/Koa DNA, suggesting the localization of the 

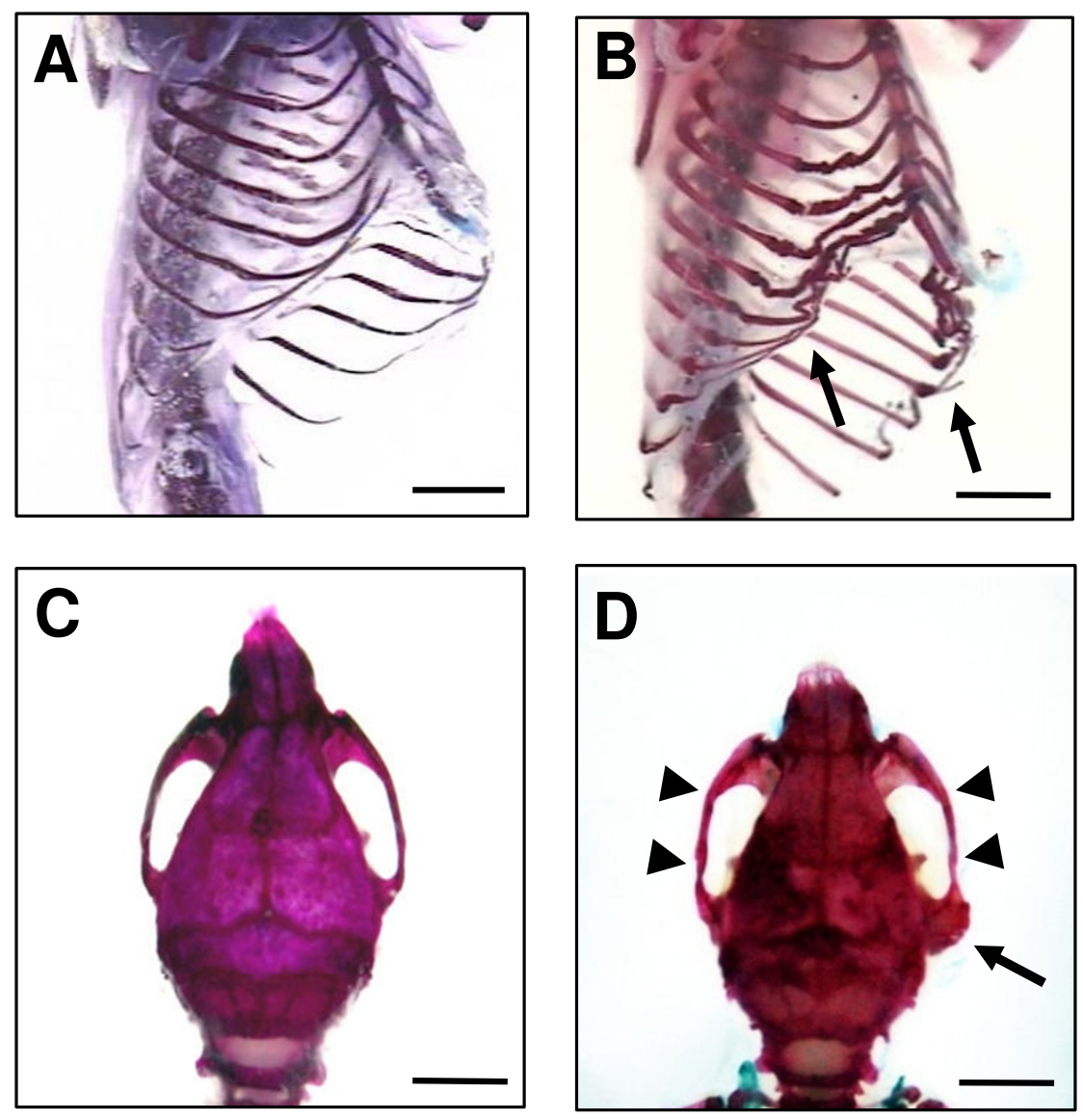

Figure 2

Skeletal phenotypes of the Koa/Koa mice. (A and B) Ventrolateral view of ribs of $+/+(A)$ and Koa/Koa (B) mice. Arrows indicate abnormal curvature of the ribs in Koa/Koa mice. (C and D) Skull of $+/+(C)$ and Koa/Koa (D) mice with dorsal views. Arrowheads and arrows indicate expanded zygomatic arches and deformed zygomatic processes of Koa/Koa mice, respectively.

distal breakpoint in this fragment. To determine the exact sites of both breakpoints, we performed PCR amplification using primer pairs Prox-f and Dist-f, and Prox-r and Dist-r to amplify recombinant fragments containing the breakpoints (Figure 5) and their nucleotide sequences were determined. These pairs of primers amplified approximately 1 -kb fragments from the Koa/Koa DNA, but not from +/+ DNA. The nucleotide sequences of these fragments revealed that the proximal and distal breakpoints were at 51,512,764 of the mouse chromosome 15 genome sequence (Build 37.1) in a region between the Trps1 and Eif3s3 genes, and at 102,965,601 in a region between the Hoxc4 and Smug1 genes, respectively (Figure $5)$. These results were concordant with those of Fantauzzo et al. [6]. Although there were 2- and 3-bp deletions and a 1-bp insertion at the breakpoints, no gene was disrupted by the Koa inversion (Figure 5).
As shown in Figure 4, the DelB-DupD mice showing the Koa phenotype had the proximal recombinant break point of the Koa inversion, but not the distal recombinant breakpoint, whereas the DupB-DelD mice showing the Eh phenotype had the distal recombinant breakpoint, but not the proximal recombinant breakpoint. This evidence indicated that the gene(s) responsible for the Koa phenotype is located in the vicinity of the proximal recombinant breakpoint and, therefore excluded the genes on the distal recombinant breakpoint from the candidate genes.

\section{Expression of genes in the vicinity of the breakpoints}

To examine whether or not altered expression of the genes located near the proximal recombinant breakpoints is the cause of the Koa phenotypes, we compared expression levels of the Hoxc4, Hoxc13, and Trps1 genes, which are the most likely candidate genes for the phenotypes of the Koa mouse in these regions, among E14.5 +/+, Koa/+, and Koa/ Koa embryos by semi-quantitative RT-PCR. While expres- 
Table 2: Incidence of open eyelids at birth (EOB) phenotype in different genotypes

\begin{tabular}{ccccc}
\hline & Bilateral EOB & Unilateral EOB & Normal & Total \\
\hline$+/+$ & 0 & 0 & 12 & 12 \\
Koal+ & 2 & 0 & 28 & 30 \\
KoalKoa & 18 & 1 & 2 & 21 \\
\hline
\end{tabular}

sion of Hoxc4 and Hoxc13 showed no apparent difference among these embryos, expression of Trps 1 was markedly reduced in the Koa/+ and Koa/Koa embryos (Figure 6), indicating that the chromosomal inversion resulted in altered expression of the Trps1 gene.

\section{Discussion}

In the present study, we confirmed the breakpoints of the Koa inversion by a genetic method using mice with the Koa and Eh recombinant chromosomes. Since no gene was disrupted by the Koa inversion, the phenotypes of the Koa mice were suggested to be caused by altered expression of gene(s) in the vicinity of the proximal and/or distal breakpoints. Next, we excluded the genes on the distal recombinant breakpoint from the candidate genes by association between the Koa phenotypes and the proximal recombinant breakpoints in DelB-DupD and DupB-DelD mice. As shown in Figure 4 , there are at least 10 functional genes (Trps1 and Hoxc4, 5, 6, 8, 9, 10, 11, 12,13) and several predicted transcriptional units in the vicinities of the proximal breakpoint. However, the reported functions of the known genes or phenotypes of the mice with disruption of these genes indicated that no genes except for the Hoxc4,Hoxc13 and Trps1 genes were likely to be involved in the phenotypes of the Koa mouse. The targeted disruptions of the Hoxc4,Hoxc13 and Trps1 genes were reported to cause defects in the thoracic vertebrae, alopecia, and abnormalities in the vibrissae, skull and thoracic vertebrae, respectively [10-12]. Therefore, we examined the expressions of these genes and found that the expression of the Trps1 gene was significantly reduced in the Koa/Koa and Koa/+ embryos while no significant difference was observed in the Hoxc4 and Hoxc13 genes. These findings strongly suggested that the reduced expression of the Trsp1 gene caused by chromosomal inversion is responsible for the phenotypes of the Koa/Koa mice.

The Trps 1 gene encodes one of the GATA transcriptional factors defined by the presence of zinc finger motifs with
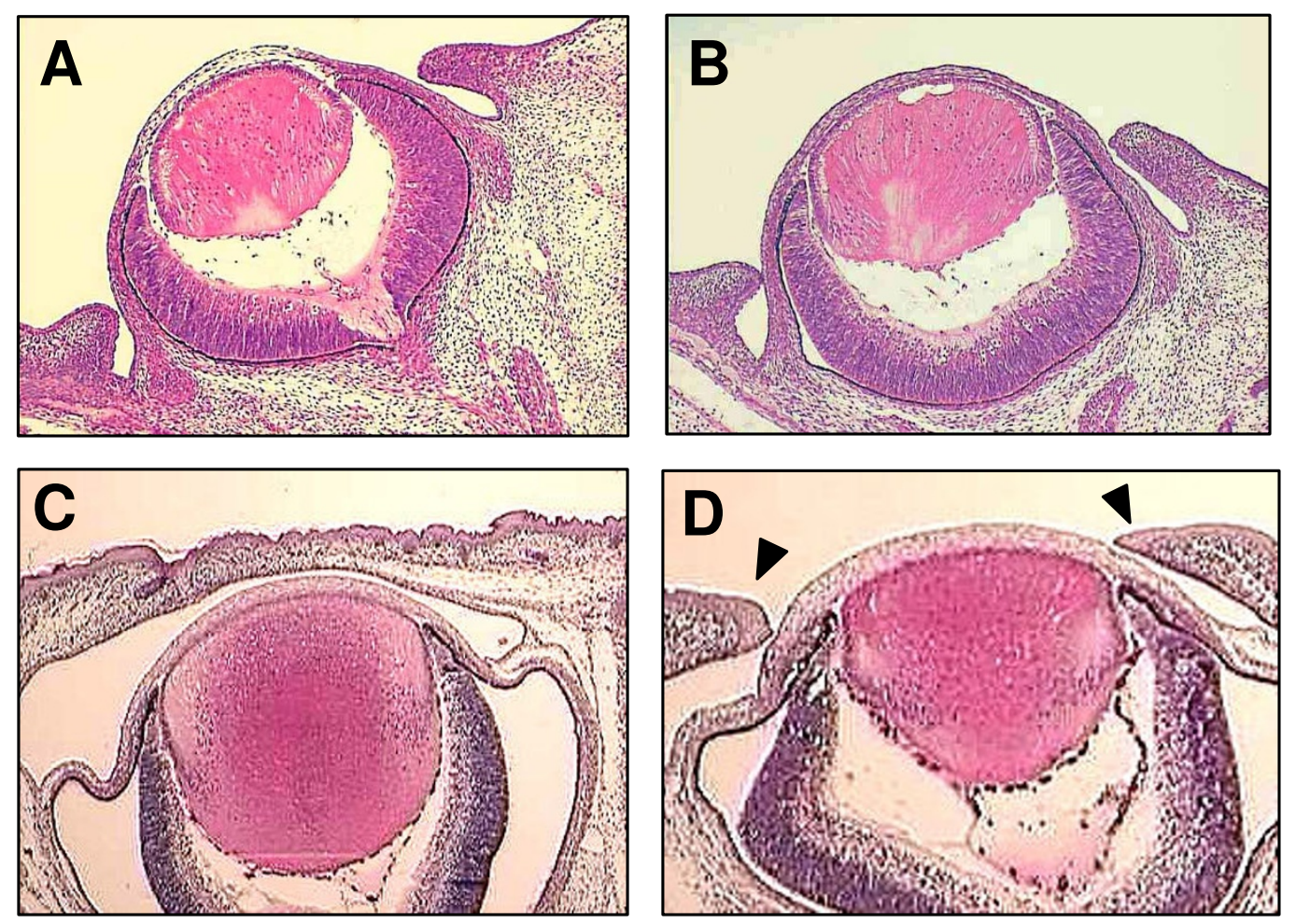

Figure 3

Developing eyes of the Koa/Koa mice. (A and B) Eyelids of EI4.5 +/+ (A) and Koa/Koa (B) embryos. (C and D) Eyelids of $\mathrm{EI} 6.5+/+(\mathrm{C})$ and Koa/Koa (D) embryos. Arrowheads indicate eyelids that were not fused with each other. 


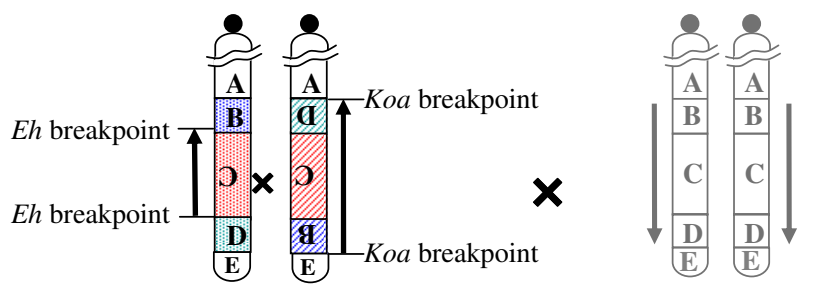

$E h+/+$ Koa

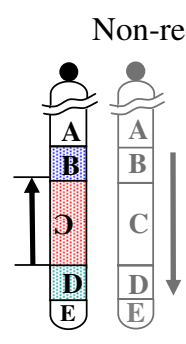

$E h /+$

Number of mice $\quad 20$

Phenotype
Eh

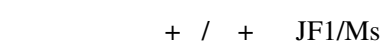

\section{$\downarrow$}

$+/+\mathrm{JF} 1 / \mathrm{Ms}$

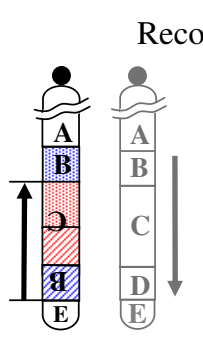

DupB-DelD / +

13

Eh

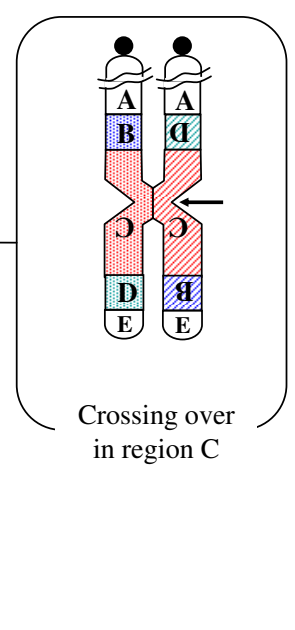

DelB-DupD /+

15

Koa

\section{Figure 4}

Schematic diagram of recombinant chromosomes resulting from crossover between overlapping regions of Koa and Eh inversions. The Eh $+/+$ Koa double heterozygote has both Koa type and Eh type chromosomes. If crossover occurred in the overlapping region of the two inversions ( $C$ region), recombinant chromosomes with duplication of the $B$ region and deletion of the $D$ region (DupB-DelD), or with deletion of the $B$ region and duplication of the $D$ region (DelBDupD), were transmitted to the offspring. The phenotypes of mice with these chromosomes are indicated at the bottom.

a consensus sequence and has essential functions in vertebrate development [13-16]. Trps1 is widely expressed during embryogenesis, including expression within developing ribs, limbs, digits, vertebrae, snout, hair follicles and skin surrounding the eyes $[17,18]$, and regulates chondrogenesis [19-21]. Mutations of TRPS1 in humans cause autosomal-dominant hereditary diseases, trichorhino-phalangeal syndromes (TRPS) type I and III, and patients with TRPS exhibit craniofacial malformation, bone abnormalities and sparse scalp hair [22-24]. In addition, targeted disruption of the Trps1 gene in the mouse causes craniofacial abnormalities, kyphoscoliosis and reduced trabecular bone in heterozygous mice, and a lack of vibrissae, scoliosis and abnormalities in the thoracic spine and ribs in homozygous mice [12]. In the present study, we found that Koa/Koa showed skull and rib deformities and a reduced number of vibrissae hair follicles, which resembled the phenotypes of the Trps1-deficient mice. These phenotypic similarities also suggested the involvement of Trps1 in the Koa phenotypes. In addition, the impaired extension of the eyelids of Koa/Koa mice can be explained by the function of the Trsp1 gene, since Trps1 is expressed in the skin surrounding the eyes during embryonic development [17].

Although localization of the breakpoints of the Koa inversion and reduced expression of Trsp 1 have been reported by Fantauzzo et al. [6], they could not rule out the possibility that the other genes in the vicinities of the breakpoints are responsible for the Koa phenotype. However, our findings including an association between the Koa phenotype and the proximal recombinant breakpoint, the normal expression of the Hoxc4 and Hoxc13 genes in Koa mice, and phenotypic similarities with Trps1-deficient mice or human patients with TRSP1 mutations, provide novel evidence indicating that the Trps1 gene, but not the other genes in the vicinities of the breakpoints, is responsible for the Koa phenotype.

In addition to the skeletal anomalies, the Koa/+ and Koa/ Koa mice showed extra hair on the pinna and a bushy muzzle, which were not reported in the Trps1-deficient 

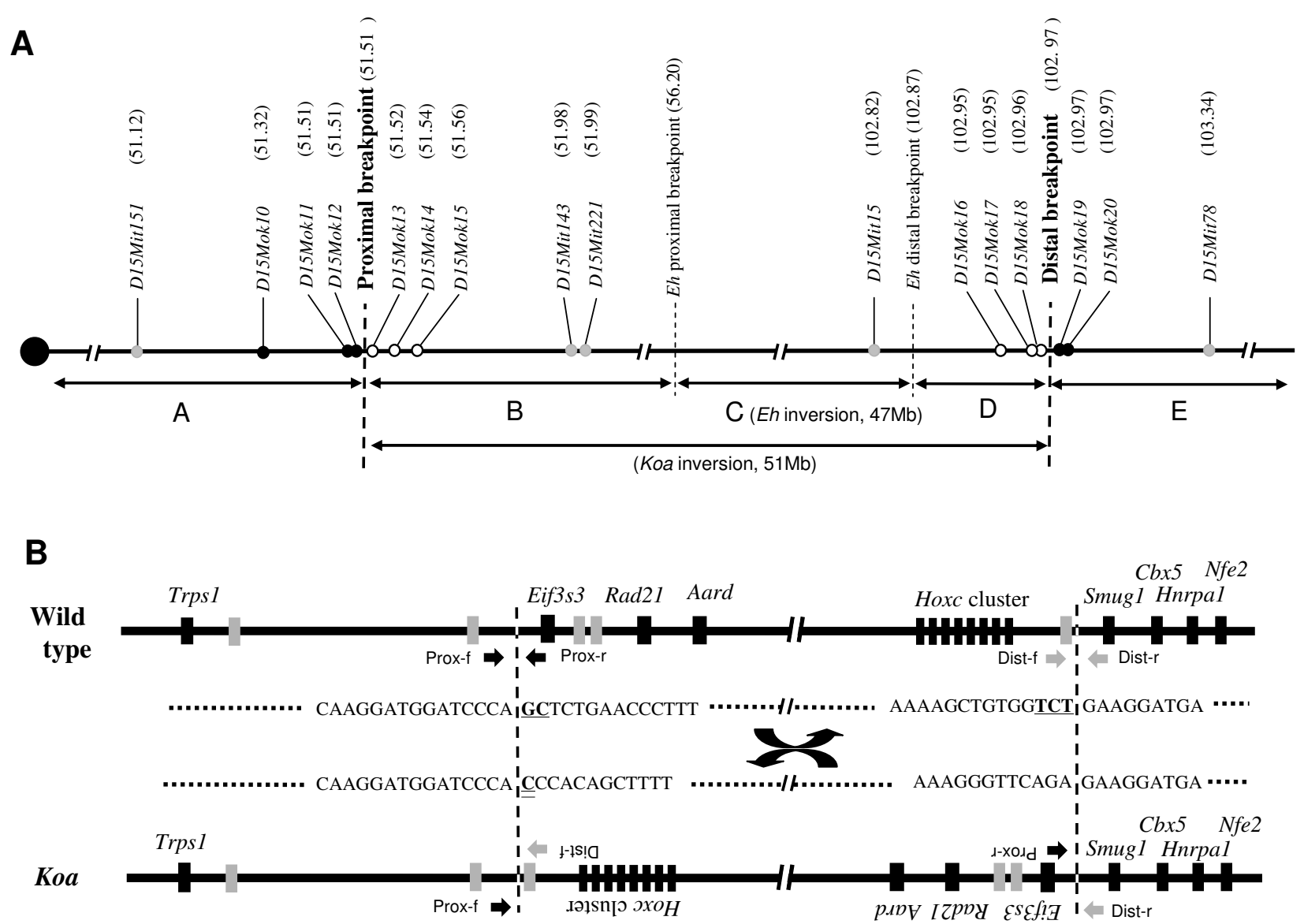

Proximal breakpoint

Distal breakpoint

Figure 5

Schematic diagram of the breakpoints of the Koa inversion. (A) Map of mouse chromosome 15 showing positions of microsatellite markers surrounding the proximal and distal breakpoints. Numbers in parentheses indicate the position in the mouse genome sequence (Build 37.I). Markers showing hemizygosity and heterozygosity in mice with recombinant chromosomes are indicated by open and filled circles, respectively. Gray circles indicate markers used in the previous linkage analysis [8]. A, B, C, D and E represent the corresponding regions in Figure 4. (B) Genomic structure and nucleotide sequences of the breakpoints of the Koa inversion. Underlined and double underlined letters represent deleted and inserted nucleotides at the breakpoints, respectively. Filled and gray boxes represent functional genes and predicted transcriptional units with unknown function, respectively. Arrows indicate primers for cloning of the breakpoints.

mice. Since the proximal breakpoint of the Koa inversion is located approximately $0.8-\mathrm{Mbp}$ apart from $\operatorname{Trps} 1$, these differences in the phenotypes between Koa and Trps1-deficient mice could be reflected by the different types of mutations. Chromosomal rearrangements often affect the expression pattern of the genes located near the breakpoint by a position effect. The position effects of cis-regulatory elements on transcription of genes have been well documented in mutant mice involving the Shh gene [2527]. Mice having mutations or chromosomal rearrangements involving the cis-regulatory elements of the Shh gene share several phenotypic features similar to those of
Shh-deficient mice, but some of them also exhibit phenotypes not observed in Shh-deficient mice. These differences are thought to be caused by ectopic expression of Shh during embryogenesis [3,27]. Therefore, the differences in the phenotypes between the Koa mice and Trps1deficient mice may be due to the ectopic expression of Trps1 during embryogenesis caused by chromosomal inversion.

It is notable that almost no expression of the Trps1 gene was observed not only in the Koa/Koa homozygous mice, but also in the $\mathrm{Koa} /+$ heterozygous mice (Figure 1), 


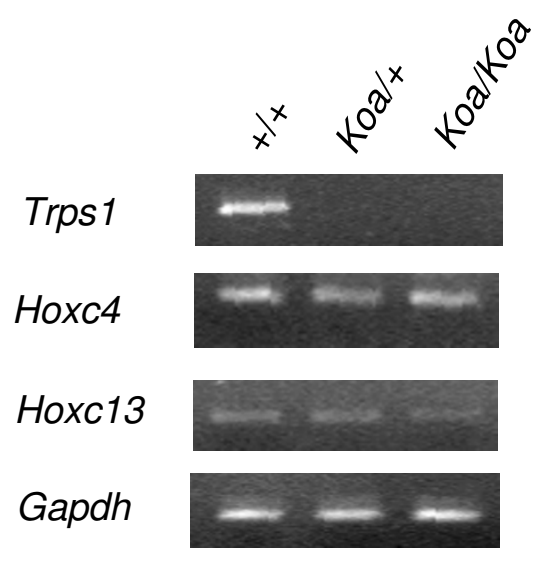

\section{Figure 6}

Expression of candidate genes in mouse embryos. Expression levels of Trps I, Hoxc4, and Hoxcl 3 genes were compared among El4.5 +/+, Koal+, and Koa/Koa embryos. Expression of Gapdh was used as a standard.

although they have one wild-type chromosome. This unexpected level of Trps1 expression in Koa/+ mice is the same as that reported in Fantauzzo et al. [6] and is concordant with the dominant mode of inheritance of the Koa mutation. One possible mechanism for the dominant suppression of the Trps1 expression in Koa mice is that transcription of antisense RNA of the Trps1 gene is enhanced by the chromosomal inversion resulting in suppression of the sense Trps1 transcription from both mutant and wild-type chromosomes. Tufarelli et al. reported that expression of antisense RNA caused by a deletion in a region close to the $\alpha$-globin gene resulted in methylation of a nearby CpG island and silencing of the $\alpha$-globin gene expression [28]. A similar mechanism may be involved in the dominant suppression of Trps1 expression in the Koa mice.

\section{Conclusion}

In the present study, we found skeletal abnormalities in Koa/Koa mice and determined the breakpoints of the Koa chromosomal inversion. While no gene was disrupted by the chromosomal inversion, expression of the Trsps1 gene, which is localized close to the proximal breakpoint, was significantly reduced in Koa mice. The present findings including the association between the Koa phenotype and the proximal recombinant breakpoint, phenotypic similarities with Trps1-deficient mice or human patients with TRSP1 mutations, and the reduced expression of the Trsps1 gene and normal expression of Hoxc4 and Hoxc13 genes, indicated that the phenotypes of the Koa mice, at least to some extent, are caused by altered expression of the Trps1gene.

\section{Methods \\ Animals}

Koa and Eh mutant mice were obtained from the Medical Research Council (Harwell, Oxfordshire, UK) and the Jackson Laboratory (Bar Harbor, Maine, USA), respectively. JF1/Ms mice were obtained from the National Institute of Genetics (Mishima, Japan). The genotypes of the mice were determined by PCR using primers flanking the breakpoints of the inversion (Additional File 1). Body length from the nose to the anus and body weight of $5+/$ ,$+ 5+/ K o a$, and 3 Koa/Koa mice were measured every 2 days until P20. All data are expressed as the means \pm SD, and the statistical significance of differences was determined using the Student's t-test.

\section{Skeletal and histological preparations}

Koa/Koa, Koa/+, and +/+ adult mice were used for skeletal preparation. The skin and internal organs of the mice were removed. The skeletons were fixed in 95\% ethanol for 1 day and then stained with $0.15 \%$ alcian blue in $80 \%$ ethanol and 20\% acetic acid for 1 day. Fixed skeletons were dehydrated in 100\% ethanol and immersed in $2 \% \mathrm{KOH}$ for 1-7 days. The skeletons were then stained with $0.015 \%$ alizarin red in $1 \% \mathrm{KOH}$ for 1 day, cleared in a series of graded glycerin, and stored in glycerin and ethanol (1:1). Mouse embryos were fixed in 4\% paraformaldehyde for 16-24 hrs at room temperature. After dehydration, the embryos were embedded in paraffin and sectioned at 4 $\mu \mathrm{m}$ thickness. Hematoxylin and eosin-stained sections were observed under a light microscope.

\section{Generation of recombinant chromosomes and localization of the breakpoints}

$\mathrm{Koa} /+$ mice were mated with $\mathrm{Eh} /+$ mice to obtain $\mathrm{Koa}+/+$ Eh mice, which have both the Koa and Eh inversions. The $\mathrm{Koa}+/+$ Eh mice were then mated with mice of the JF1/Ms strain, and 60 offspring were obtained. Genomic DNAs were prepared from mouse livers by phenol/chloroform extraction. To determine the deleted or duplicated region of the recombinant chromosomes, the genotypes of 11 new microsatellite markers obtained from the genomic sequence of this region were determined. The genotypes were obtained by PCR amplification in a reaction mixture containing $20 \mathrm{ng}$ of genomic DNA, $0.2 \mathrm{mM}$ dNTP, $0.2 \mu \mathrm{M}$ of each primer and $0.25 \mathrm{U}$ of Taq DNA polymerase (Amersham Bioscience, Piscataway, NJ, USA) with 35 cycles at $94^{\circ} \mathrm{C}$ for $30 \mathrm{sec}, 50-60^{\circ} \mathrm{C}$ for $30 \mathrm{sec}$ and $72^{\circ} \mathrm{C}$ for $30 \mathrm{sec}$. The PCR products were electrophoresed on $3.0 \%$ agarose gel and stained with ethidium bromide. Primer information for these microsatellite markers is shown in Additional file 1 . The exact breakpoints of the inversion were determined by a series of PCR amplifications of 1- to 2-kb fragments in the critical region. The PCR products were cloned into pGEM-T Easy vector (Promega, Madison, WI, USA) and sequenced by an ABI310 automated sequencer. 


\section{Expression analysis of genes in the vicinities of the breakpoints}

E15.5 embryos of each genotype were obtained from mating between $\mathrm{Koa} /+$ mice. Total RNA was extracted from the embryos and reverse transcribed using Superscript III reverse transcriptase (Invitrogen, Carlsbad, CA, USA) with random hexamers for $60 \mathrm{~min}$ at $42^{\circ} \mathrm{C}$. The expression of candidate genes in the vicinities of the breakpoints was examined by semi-quantitative RT-PCR under the following conditions: 30 - 40 cycles consisting of denaturation at $94^{\circ} \mathrm{C}$ for $30 \mathrm{sec}$, annealing at $50-55^{\circ} \mathrm{C}$ for $30 \mathrm{sec}$, and extension at $72^{\circ} \mathrm{C}$ for $30 \mathrm{sec}$. Primer information for the RT-PCR is shown in Additional file 1.

\section{Authors' contributions}

KK carried out the molecular genetic studies and drafted the manuscript. SM participated in molecular genetic studies and carried out morphological studies. AF participated in molecular genetic and morphological studies. KA and TT participated in mouse breeding and sequence alignment. ST and HS helped to draft the manuscript. TK conceived the study, carried out its design and coordination, and helped to draft the manuscript. All authors read and approved the final manuscript.

\section{Additional material}

\section{Additional file 1}

Supplemental table S1. Nucleotide sequences of primers for PCR. Click here for file

[http://www.biomedcentral.com/content/supplementary/1471-

2156-10-60-S1.DOC]

\section{Acknowledgements}

This work was partially supported by Sasakawa Science Research Grant from the Japan Science Society.

\section{References}

I. Beechey CV: List of chromosome anomalies. Mouse Genome 1994, 92:336-347.

2. Hagiwara N, Klewer SE, Samson RA, Erickson DT, Lyon MF, Brilliant $\mathrm{MH}$ : Sox6 is a candidate gene for $p^{100 H}$ myopathy, heart block, and sudden neonatal death. Proc Natl Acad Sci USA 2000, 97:4180-4185.

3. Niedermaier M, Schwabe GC, Fees S, Helmrich A, Brieske N, Seemann P, Hecht J, Seitz V, Stricker S, Leschik G, Schrock E, Selby PB, Mundlos S: An inversion involving the mouse Shh locus results in brachydactyly through dysregulation of Shh expression. J Clin Invest 2005, I I 5:900-909.

4. Ball ST, Peters L: Koala, a dominant mutation. Mouse News Lett 1989, 83: I63-164

5. Peters J, Tease C, Ball ST: Koala, Koa, is associated with an inversion on mouse chromosome 15. Genet Res 1992, 59:237-238.

6. Fantauzzo KA, Tadin-Strapps M, You Y, Mentzer SE, Baumeister F, Cianfarani S, Van Maldergem L, Warburton D, Sundberg JP, Christiano AM: A position effect on TRPSI is associated with Ambras syndrome in humans and the Koala phenotype in mice. Hum Mol Genet 2008, I 7:3539-355I.
7. Davisson MT, Roderick TH, Akeson EC, Hawes NL, Sweet HO: The hairy ears (Eh) mutation is closely associated with a chromosomal rearrangement in the mouse chromosome I5. Genet Res 1990, 56:167-178.

8. Katayama K, Furuno A, Miyamoto S, Nakamura M, Ojika I, Shinkai Y, Akiyama K, Tsuji T, Kunieda T: Suppressed recombination on mouse chromosome 15 defined regions of chromosomal inversions associated with Koala (Koa) and Hairy ears (Eh) mutations. Exp Anim 2008, 57:73-77.

9. Katayama K, Furuno A, Akiyama K, Tsuji T, Kunieda T: Characterization of chromosomal inversion of the mouse hairy ears (Eh) mutation associated with cleft palate. Mamm Genome 2007, I 8:246-254.

10. Boulet AM, Capecchi MR: Targeted disruption of hoxc-4 causes esophageal defects and vertebral transformations. Dev Biol 1996, I77:232-249.

II. Godwin AR, Capecchi MR: Hoxcl3 mutant mice lack external hair. Genes Dev 1998, I2: I I-20.

12. Malik TH, Von Stechow D, Bronson RT, Shivdasani RA: Deletion of the GATA domain of TRPSI causes an absence of facial hair and provides new insights into the bone disorder in inherited tricho-rhino-phalangeal syndromes. Mol Cell Biol 2002, 22:8592-8600.

13. Koutsourakis M, Langeveld A, Patient R, Beddington R, Grosveld F: The transcription factor GATA6 is essential for early extraembryonic development. Development 1999, I 26:723-732.

14. Kuo CT, Morrisey EE, Anandappa R, Sigrist K, Lu MM, Parmacek MS, Soudais C, Leiden JM: GATA4 transcription factor is required for ventral morphogenesis and heart tube formation. Genes Dev 1997, I I: 1048-1060.

15. Pandolfi PP, Roth ME, Karis A, Leonard MW, Dzierzak E, Grosveld FG, Engel JD, Lindenbaum MH: Targeted disruption of the GATA3 gene causes severe abnormalities in the nervous system and in fetal liver haematopoiesis. Nat Genet 1995, I I :40-44.

16. Tsai FY, Keller G, Kuo FC, Weiss M, Chen J, Rosenblatt M, Alt FW, Orkin SH: An early haematopoietic defect in mice lacking the transcription factor GATA-2. Nature 1994, 37 I:221-226.

17. Kunath M, Lüdecke H-J, Vortkamp A: Expression of Trps I during mouse embryonic development. Mech Dev 2002, I I9S:SII7-SI20.

18. Malik TH, Shoichet SA, Latham P, Kroll TG, Peters LL, Shivdasani RA: Transcriptional repression and developmental functions of the atypical vertebrate GATA protein TRPSI. EMBO J 200I, 20:1715-1725.

19. Napierala D, Sam K, Morello R, Zheng Q, Munivez E, Shivdasani RA, Lee $B$ : Uncoupling of chondrocyte differentiation and perichondrial mineralization underlies the skeletal dysplasia in tricho-rhino-phalangeal syndrome. Hum Mol Genet 2008, I 7:2244-2254.

20. Nishioka K, Itoh S, Suemoto H, Kanno S, Gai Z, Kawakatsu M, Tanishima $\mathrm{H}$, Morimoto $\mathrm{Y}$, Hatamura I, Yoshida M, Muragaki Y: Trps I deficiency enlarges the proliferative zone of growth plate cartilage by upregulation of Pthrp. Bone 2008, 43:64-7I.

21. Suemoto H, Muragaki Y, Nishioka K, Sato M, Ooshima A, Itoh S, Hatamura I, Ozaki M, Braun A, Gustafsson E, Fässler R: Trps I regulates proliferation and apoptosis of chondrocytes through Stat3 signaling. Dev Biol 2007, 3 I 2:572-58I.

22. Gentile M, Fiorente P, Buonadonna AL, Macina F, Cariola F: A novel mutation in exon 7 in a family with mild tricho-rhino-phalangeal syndrome type I. Clin Genet 2003, 63:166-167.

23. Kobayashi H, Hino M, Shimodahira M, Iwakura T, Ishihara T, Ikekubo K, Ogawa Y, Nakao K, Kurahachi H: Missense mutation of TRPSI in a family of tricho-rhino-phalangeal syndrome type III. Am J Med Genet 2002, I 07:26-29.

24. Momeni P, Glöckner G, Schmidt O, von Holtum D, Albrecht B, Gillessen-Kaesbach G, Hennekam R, Meinecke P, Zabel B, Rosenthal A, Horsthemke $B$, Lüdecke $H$-J: Mutations in a new gene, encoding a zinc-finger protein, cause tricho-rhino-phalangeal syndrome type I. Nat Genet 2000, 24:7|-74.

25. Kleinjan DA, van Heyningen V: Long-range control of gene expression: emerging mechanisms and disruption in disease. Am J Hum Genet 2005, 76:8-32.

26. Krebs O, Schreiner CM, Scott WJ Jr, Bell SM, Robbins DJ, Goetz JA, Alt H, Hawes N, Wolf E, Favor J: Replicated anterior zeugopod 
(raz): a polydactylous mouse mutant with lowered Shh signaling in the limb bud. Development 2003, 130:6037-6047.

27. Sagai T, Hosoya M, Mizushina Y, Tamura M, Shiroishi T: Elimination of a long-range cis-regulatory module causes complete loss of limb-specific Shh expression and truncation of the mouse limb. Development 2005, 132:797-803.

28. Tufarelli C, Stanley JA, Garrick D, Sharpe JA, Ayyub H, Wood WG, Higgs DR: Transcription of antisense RNA leading to gene silencing and methylation as a novel cause of human genetic disease. Nat Genet 2003, 34:157-165.

Publish with Bio Med Central and every scientist can read your work free of charge

"BioMed Central will be the most significant development for disseminating the results of biomedical research in our lifetime. " Sir Paul Nurse, Cancer Research UK

Your research papers will be:

- available free of charge to the entire biomedical community

- peer reviewed and published immediately upon acceptance

- cited in PubMed and archived on PubMed Central

- yours - you keep the copyright

Submit your manuscript here:

http://www.biomedcentral.com/info/publishing_adv.asp
BioMedcentral 